\title{
REHABILITATION: A CRUCIAL COMPONENT IN THE FUTURE OF HIV CARE AND SUPPORT
}

\author{
Stephanie Nixon, BHSc (Physiotherapy), PhD \\ Department of Physical Therapy, University of Toronto, Canada, International Centre for Disability and Rehabilitation, Canada, and Health Eco- \\ nomics and HIV/AIDS Research Division (HEARD), University of KwaZulu-Natal, South Africa \\ Lisa Forman, $L L B$, $S J D$ \\ Dalla Lana School of Public Health and Munk School of Global Affairs, University of Toronto, Canada
}

Jill Hanass-Hancock, DrPhill

HEARD, University of KwaZulu-Natal, South Africa

Muriel Mac-Seing, BScN (Nursing), MSc

Handicap International, Kenya

Norbert Munyanukato, $M D$

UNHCR/COOPI, Chad

Hellen Myezwa, MCSP (Physiotherapy), PhD

Department of Physiotherapy, University of the Witwatersrand, South Africa

Chiara Retis, BSc (Physiotherapy)

Handicap International, France

\begin{abstract}
Provision of antiretroviral therapy (ART) is not an end in itself but a means to achieving improved wellness for people living with HIV. Rehabilitation, broadly defined, is another key contributor to wellness within this context. Understanding the potential for rehabilitation requires that one is able to consider HIV not only within a biomedical model that focuses on body systems, diagnoses and symptoms, but also within a rehabilitation framework that focuses on how these diagnoses and symptoms affect people's lives more broadly. Furthermore, rehabilitation is a human rights imperative, which deserves the energetic attention enjoyed by other aspects of HIV treatment and care. In particular, the United Nations Convention on the Rights of Persons with Disabilities (UNCRPD) is shining a long-overdue spotlight on the human rights imperatives associated with disability. For South Africa and other countries, proactively and meaningfully engaging rehabilitation in the HIV response will require major shifts on several fronts, including practice, education, policy and research. We argue that in settings where ART delivery is now widespread, HIV should be understood not only as a medical issue, but as a rehabilitation and disability concern. Whereas medicine adds years to life, it is rehabilitation that aims to add life to years.
\end{abstract}

\section{THE LATE 1990s: THE BIRTH OF REHABILITATION IN THE CONTEXT OF HIV IN HIGH-INCOME COUNTRIES}

Until 1995, an HIV diagnosis meant largely the same thing regardless of where one lived globally: people living with HIV typically experienced various HIV-related diseases that progressed steadily until death. In 1996, however, early forms of triple-combination antiretroviral therapy (ART) became available and life with HIV changed dramatically for people who could access and tolerate these medications - the vast majority of whom lived in high-income countries.

With the advent of ART, people with HIV began to live longer, which was a cause for great celebration. ${ }^{1}$ However, the experience of living with HIV was not without continuing challenges. Along with their existing symptoms, many people living with HIV described an unexpected experience of disablement related to primary infection from HIV, HIV-related conditions, and side-effects of ART. ${ }^{2,3}$ As their needs changed, so did the way that clinicians and advocates thought about HIV. In Canada, a key response came from the rehabilitation community. ${ }^{4}$

Rehabilitation as a field aims to help people address the life-related consequences of medical conditions. As such, an early response to the shift in experience brought about by the advent of ART was to reconceptualise HIV out of a biomedical model and into a rehabilitation framework. In contrast to an exclusive biomedical focus on diagnoses, symptoms and medications, the World Health Organization's rehabilitation framework, the International Classification of Disability, Functioning and Health (ICF), served to refocus attention on the related 'impairments' (problems with body structure or function), 'activity limitations' (challenges at the level of the whole body) and 'participation restrictions' (challenges related to the person in her/his environment) associated with HIV. ${ }^{6}$ Rehabilitation is broadly defined as any services, policies or other actions that respond to these challenges. 
The reconceptualisation of HIV within a rehabilitation framework enabled people living with HIV and their advocates to articulate their experiences and needs differently. ${ }^{7}$ This in turn encouraged health care providers to consider the rehabilitation care needs of their clients more comprehensively. ${ }^{8}$ This reframing offered HIV researchers a strategy for measuring the prevalence of disability among people living with HIV, which was found to be strikingly high. ${ }^{2,9}$ It also led researchers to explore novel dimensions of life with HIV in this new era, such as 'episodic disability'. ${ }^{10-13}$ Finally, but not least, this re-orientation prompted policy-makers to meaningfully include rehabilitation and disability in their strategic responses to HIV. ${ }^{14}$ Rehabilitation in the context of HIV is now well entrenched in the HIV response in Canada. ${ }^{15}$

\section{THE LATE 2000s: THE REBIRTH OF}

REHABILITATION IN THE CONTEXT OF HIV IN

\section{LOW- AND MIDDLE-INCOME COUNTRIES}

Since the mid-2000s, after years of dynamic activism to bridge profound inequities in treatment delivery, access to ART has at last begun to improve in many resourcepoor countries with a high HIV prevalence. ${ }^{16} \mathrm{ART}$ is a crucially important advance in contributing to the health and well-being of people living with HIV. However, it has been hypothesised that the widespread scale-up of ART in sub-Saharan Africa will prompt experiences of disablement related to HIV, its secondary conditions and side-effects of medication, similar to those in Canada in the mid-1990s. ${ }^{17,18}$ Indeed, the first studies exploring disablement among people living with HIV in southern Africa support this hypothesis: Myezwa, Van As and colleagues used the WHO-ICF framework to reveal a high level of disablement among 80 people living with HIV who were hospital inpatients, ${ }^{19}$ as well as 45 clinic outpatients in South Africa. ${ }^{20}$

In addition to formal evidence, rehabilitation providers on the ground are witnessing the disabling effects of HIV and the medications used to treat it. For example, Handicap International, an international NGO that supports the development of rehabilitation services in 13 African countries, reports that their rehabilitation programmes in Kenya, Ethiopia and Mozambique are increasingly witnessing the arrival of people living with HIV seeking rehabilitation services. Similarly, the South African Disability Alliance in co-operation with the South African National AIDS Council identified that people living with HIV are at increased risk for developing disability. ${ }^{21}$ Furthermore, a recent research meeting in KwaZulu-Natal identified the disabling effects of HIV as a priority. ${ }^{22}$ We argue that this is the beginning of a trend that will see rehabilitation become a key component of HIV care. For South Africa and other countries, proactively engaging rehabilitation in the HIV response will require major shifts on several fronts.

\section{ADVANCING OUR PRACTICE AND EDUCATION}

Provision of ART is not an end in itself, but rather a means to achieve improved wellness for people living with HIV. Rehabilitation, broadly defined, is another key contributor to wellness within this context. Understanding and engaging rehabilitation requires that one is able to consider HIV not only within a biomedical model that focuses on body systems, diagnoses and symptoms, but also within a rehabilitation framework that refocuses on how physical and mental health diagnoses and symptoms affect people's lives. The World Health Organization's ICF contributed importantly to a paradigm shift in Canada. The ICF is also a leading rehabilitation framework in the global South that has much to offer HIV. Reconceptualising HIV through a rehabilitation lens highlights opportunities for enhanced HIV practice and education relevant for at least three broad populations.

First, people and organisations who provide HIV health services should come to understand the role of rehabilitation within the continuum of care. This is particularly true for HIV care providers who, as the point of contact with people living with HIV, are uniquely situated to provide referrals to rehabilitation services. HIV providers must be trained to understand the impairments, activity limitations and participation restrictions that can arise from HIV-related conditions, and the options available within the world of rehabilitation to address these concerns.

Second, we call on the rehabilitation and disability communities to recognise their role in responding to the needs of people living with HIV and their communities, including physiotherapists, occupational therapists, speech-language therapists, audiologists, prosthetics and orthotics specialists and the wide range of other rehabilitation providers for people living with HIV. However, education on the role of rehabilitation for people living with HIV also needs to reach community-based workers, health volunteers and community leaders, as these front-line workers are frequently the information links for people in need of rehabilitation. Shortages of all forms of health human resources demand a different approach to rehabilitation delivery to that in the North. However, existing models of communitybased rehabilitation have been driving service delivery for decades and have a range of similarities with HIV home-based care. Overburdened health systems require that, like all aspects of the HIV response, we must seek synergies for providing rehabilitation within the broader health system, rather than implementing services within a purely vertical response.

Third, and arguably most importantly, is for people living with HIV and their advocacy partners to recognise the robust role that rehabilitation can play in the future of the HIV response and to include calls for action from stakeholders. Historically, it has been people living with HIV who were most effective at prompting change. Rehabilitation in the context of HIV needs to be recognised as a new target for advocacy and lobbying, which points to change at the policy level.

\section{ADVANCING OUR POLICIES}

Rehabilitation is a human rights imperative and therefore deserves the kind of energetic attention enjoyed by other aspects of HIV treatment and care. One major advantage for the rehabilitation response in this new era of ART scale-up is the recent passing of the United Nations 
Convention on the Rights of Persons with Disabilities (UNCRPD), which is shining a long-overdue spotlight on issues of disability. The Convention requires states to recognise that where people living with HIV have impairments which, in interaction with the environment, result in stigma, discrimination or other barriers to their participation, they fall under the protection of the Convention. ${ }^{23}$

The South African government is an instructive example insofar as it is bound by the human rights imperative to rehabilitate under international and national law. South Africa has ratified the UNCRPD, which recognises people's right to habilitation and rehabilitation. This requires the state to take steps to allow people with disabilities to achieve maximum independence, full physical, mental, social and vocational ability, and full inclusion and participation in all aspects of life, including through comprehensive habilitation and rehabilitation services and programmes, particularly in the areas of health (article 26). This duty is reinforced in the prohibition of unfair discrimination on the grounds of disability in the South African Constitution (section 9.3), and within related protections contained in subsidiary legislation and policy, including the Social Assistance Act of 2004, the Employment Equity Act of 1998, and the Integrated National Disability Strategy of 1997.

As such, we need toensure that recognition of rehabilitation and disability are reflected in national strategic plans for HIV and other health policy instruments. ${ }^{24}$ Importantly, South Africa's 2007 - 2011 National Strategic Plan (NSP) introduced a disability sector plan in $2009 .{ }^{25}$ Under the goal of mitigating the impact of HIV and AIDS, the NSP describes the need to improve treatment, care and support for people with disabilities. However, little guidance is given for addressing the disabling effects of HIV. Furthermore, roles for rehabilitation are not explicitly described, although dimensions of rehabilitation are considered, such as goal 6 , which focuses on enabling people living with HIV to lead healthy and productive lives. ${ }^{26,27}$

Rehabilitation, therefore, is vital in terms of human rights, health outcomes and quality of life and needs to be integrated into HIV plans. Ushering in change will require 'double mainstreaming' insofar as national and provincial HIV offices will need to be aware of the rehabilitation needs of people living with HIV, and rehabilitation/disability-related authorities need to be made aware of their role in supporting people living with HIV.

\section{ADVANCING OUR RESEARCH}

Like all dimensions of the health response to HIV, evidence is required to inform effectiveness, efficiency and acceptability of potential interventions. The same is true of rehabilitation and its role as part of the HIV care continuum. This is an untapped research landscape; several examples can illustrate the potential within this field. First, good research drives not only practice but policy development and the wise distribution of scarce resources. We need to engage in research on the African continent that explores rehabilitative care as a costeffective means of improving autonomy and quality of life for all people living with disability, including people living with HIV. Second, it is not known how the concept of episodic disability, which has been a cornerstone of the response in Canada, might play out in the context of hyper-epidemics in sub-Saharan Africa. Third, the ICF concept of participation squarely engages issues of stigma and discrimination, providing a bridge between rehabilitation researchers and those working in other anti-stigma paradigms. One final illustrative example involves forecasting models of human resource needs in rehabilitation based on increased access to ART, given the expected rise in demand.

\section{CONCLUSION}

Provision of treatment has necessarily been the central focus of HIV care in recent years. However, many countries including South Africa are now at the point of identifying and grappling with new questions related to HIV care, treatment and support in this new era of ART - a scenario that is reminiscent of the experience in Canada and other resource-rich countries in the late 1990s. While we must pay close attention to the differences between the two scenarios and the contexts in which they are based, we must also seek reciprocal lessons based on similarities. Importantly, we must understand HIV not only as a medical issue, but also as a rehabilitation and disability concern in settings where ART delivery is now widespread. Indeed, whereas medicine adds years to life, it is rehabilitation that aims to add life to years.

\section{REFERENCES}

1. Palella FJ Jr, Delaney KM, Moorman AC, et al. Declining morbidity and mortality among patients with advanced human immunodeficiency virus infection. HIV Outpatient Study Investigators. N Engl J Med 1998;338(13):853-860.

2. Rusch M, Nixon S, Schilder A, Braitstein P, Chan K, Hogg RS. Impairments, activity limitations and participation restrictions: Prevalence and associations among persons living with HIVIAIDS in British Columbia. Health Qual Life Outcomes 2004:2:46.

3. O'Brien KK, Bayoumi AM, Strike C, Young NL, Davis AM. Exploring disability from the perspective of adults living with HIVIAIDS: development of a conceptual framework. Health Qual Life Outcomes 2008;6:76.

4. Worthington C, Myers T, O'Brien K, Nixon S, Cockerill R. Rehabilitation in HIVI AIDS: development of an expanded conceptual framework. AIDS Patient Care STDS 2005;19(4):258-271.

5. Nixon S, Cott C. Shifting perspectives: reconceptualizing HIV disease in a rehabilitation framework. Physiother Can 2000:52(3):189-207.

6. World Health Organization. ICF: International Classification of Functioning, Disability and Health. Geneva: WHO, 2001

7. Canadian Working Group on HIV and Rehabilitation. About us, 2011. http://www. hivandrehab.ca/EN/index.php (accessed 9 May 2011).

8. Wellesley Central Hospital, Health Canada. A Comprehensive Guide for People Living with HIV Disease, Module 7: Rehabilitation Services. Toronto: Health Canada, 1998.

9. Rusch M, Nixon S, Schilder A, Braitstein P, Chan K, Hogg RS. Prevalence of activity limitation among persons living with HIVIAIDS in British Columbia. Can J Public Health 2004;95(6):437-440.

10. Solomon P, Wilkins S. Participation among women living with HIV: a rehabilitation perspective. AIDS Care 2008;20(3):292-296

11. Nixon $S$, Renwick R. Experiences of contemplating returning to work for people living with HIVIAIDS. Qual Health Res 2003;13(9):1272-1290.

12. O'Brien K, Wilkins A, Zack E, Solomon P. Scoping the field: identifying key research priorities in HIV and rehabilitation. AIDS Behav 2010;14(2):448-458.

13. O'Brien KK, Davis AM, Strike C, Young NL, Bayoumi AM. Putting episodic disability into context: a qualitative study exploring factors that influence disability experienced by adults living with HIVIAIDS. J Int AIDS Soc 2009;12(1):5.

14. Canadian Working Group on HIV and Rehabilitation. Episodic Disabilities Network. 2009. http://www.hivandrehab.ca/EN/episodic_disabilities/episodic_disabilities_ network.php (accessed 09 May 2011).

15. Health Canada. Leading Together: Canada Takes Action on HIVIAIDS 2005-2010, 2005. http://www.leadingtogether.ca/pdf/Leading_Together.pdf (accessed 9 May 2011).

16. WHO, UNAIDS, UNICEF. Universal Access: Scaling Up Priority HIVIAIDS Interventions in the Health Sector. Progress Report 2010. 2010. http://www.who.int/ hiv/pub/2010progressreport/cover_en.pdf (accessed 9 May 2011).

17. Hanass-Hancock J, Nixon SA. The fields of HIV and disability: past, present and 
future. J Int AIDS Soc 2009;2(1):3.

18. UNAIDS. Disability and HIV Policy Brief. 2009. http://data.unaids.org/pub/ Manual/2009/jc1632 policy_brief_disability en.pdf (accessed 9 May 2011).

19. Myezwa H, Van As M, Musenge E, Nesara P. Assessment of HIV-positive in-patients using the International Classification of Functioning, Disability and Health (ICF), at Chris Hani Baragwanath Hospital, Johannesburg. African Journal of AIDS Research 2009;8(1):93-106.

20. Van As M, Myezwa $H$, Stewart A, Maleka D, Musenge E. The International Classification of Function Disability and Health (ICF) in adults visiting the HIV outpatient clinic at a regional hospital in Johannesburg, South Africa. AIDS Care 2009;21(1):50-58

21. SANAC. HIV, AIDS and Disability in South Africa, 2008. http://www.icdr.utoronto.ca/ Files/PDF/94a3663acf97d5f.pdf (accessed 9 May 2011).

22. Health Economics and HIVIAIDS Research Division (HEARD), QuadPara Association of KwaZulu-Natal. HIV and Disability Research and Advocacy Planning Meeting, August 15-16, 2010. Ashley Village, South Africa, 2010.

23. United Nations. UN Convention on the Rights of Persons with Disabilities. 2008 http://www.un.org/disabilities/default.asp?id=150 (accessed 09 May 2011).

24. Hanass-Hancock J, Strode A, Grant K. Inclusion of disability within national strategic responses to HIV and AIDS in Eastern and Southern Africa. Disability and Rehabilitation 2011 [early online], 1-8. http://informahealthcare.com/doi/pdf/10.3109 109638288.2011.573055 (accessed 9 May 2011).

25. SANAC. Nothing About Us Without Us! HIV, AIDS and Disability in South Africa, 2010. http://www.heard.org.za/downloads/nothing-about-us-without-us-hiv-aids-anddisability-in-south-africa.pdf (accessed 9 May 2011)

26. Grant KA, Strode SA, Hanass-Hancock J. Disability in National Strategic Plans on HIV and AIDS. A Review on the National Response to the Interrelations of Disability and HIV in Eastern and Southern Africa. Durban: Health Economics and HIVIAIDS Research Division, 2009.

27. SANAC HIV and AIDS and STI Strategic Plan for South Africa, 2007-2011. http://www.tsfsouthernafrica.com/guides/strat_op_plan/folder $3 / 3.6 \% 20$ South $\% 20$ Africa\%20HIV\%20and\%20AIDS\%20and\%20STI\%20Plan\%202007-11.pdf (accessed 9 May 2011). 